\title{
Simulation as an educational modality in an Anesthesiology Resident Wellness Program
}

\author{
Michelle Chiu, MD, FRCPC므
}

Received: 29 November 2016/ Accepted: 6 December 2016/Published online: 22 December 2016

(C) Canadian Anesthesiologists' Society 2016

\section{To the Editor,}

The recently published work by Dr. Chakravarti et al. outlining the development and implementation of an Anesthesiology Resident Wellness Program at the University of Saskatchewan ${ }^{1}$ is a well thought out approach to addressing the importance of maintaining resident wellness during training and beyond. I highly endorse the use of simulation as a powerful way to facilitate learning about physician wellness competencies and am gratified to learn that the authors include this educational modality in their curriculum. Although the Canadian National Anesthesiology Simulation Curriculum ${ }^{2}$ scenarios mentioned in their article do not contain specific learning objectives on physician wellness, elements of such can certainly be discussed during post-scenario debriefing at the discretion of the instructor. It is likely that the role of simulation in teaching and assessing the Intrinsic CanMEDS roles will continue to evolve and be defined as our specialty embarks upon competency-based residency training.

Conflicts of interests None declared.

Editorial responsibility This submission was handled by Dr. Hilary P. Grocott, Editor-in-Chief, Canadian Journal of Anesthesia.

\section{References}

1. Chakravarti A, Raazi M, O'Brien J, Balaton B. Anesthesiology Resident Wellness Program at the University of Saskatchewan: curriculum content and delivery. Can J Anesth 2016. DOI: 10.1007/ s12630-016-0773-0.

2. Chiи M, Tarshis J, Antoniou A, et al. Simulation-based assessment of anesthesiology residents' competence: development and implementation of the Canadian National Anesthesiology Simulation Curriculum (CanNASC). Can J Anesth 2016; 63(12): 1357-63.
M. Chiu, MD, FRCPC ( $\square)$

Department of Anesthesiology and Pain Medicine, Department

of Innovation in Medical Education, The Ottawa Hospital,

University of Ottawa, Ottawa, ON, Canada

e-mail: mchiu@ottawahospital.on.ca 